\title{
A Monte Carlo-tuned model of the flow in the NorthGRIP
}

\section{area}

\author{
Aslak GRINSTED, Dorthe DAHL-JENSEN \\ Department of Geophysics, University of Copenhagen, Juliane Maries Vej 30, DK-2100 Copenhagen, Denmark \\ E-mail: ag@gfy.ku.dk
}

\begin{abstract}
The North Greenland Icecore Project (NorthGRIP) drill site was chosen in order to obtain a good Eemian record. At the present depth, $3001 \mathrm{~m}$, the Eemian interstadial has yet to be seen. Clearly the flow in this area is poorly understood and needs further investigation. After a review of specific features of the bottom topography, it is believed that the geology changes along the flowline. In order to investigate whether this explains the observed age-depth relationship at NorthGRIP, the inverse Monte Carlo method has been applied to a simple model. The inversion reveals that the main reason no Eemian is observed is a high basal melt rate $\left(2.7 \mathrm{~mm} \mathrm{a}^{-1}\right)$. The melting is a consequence of a higher geothermal heat flux than the expected $51 \mathrm{~mW} \mathrm{~m}^{-2}$ of the Precambrian shield. From our analyses it is concluded that the geothermal heat flux at NorthGRIP is $98 \mathrm{~mW} \mathrm{~m}^{-2}$. The high basal melt rate also gives rise to sliding at the bed. In addition to these results, an accumulation model has been established specifically for NorthGRIP. These results are essential for further modelling of the NorthGRIP flow and depth-age relationship.
\end{abstract}

\section{HISTORY}

In 1992/93, the two deep drilling projects GRIP (Greenland Icecore Project) and GISP2 (Greenland Ice Sheet Project 2) were completed. These two drillings were situated at the summit of the Greenland ice sheet, only $28 \mathrm{~km}$ apart. ${ }^{1}$ The stableisotope records have been measured for these cores in order to establish a palaeoclimatic history (Dansgaard and others, 1993; Grootes and others, 1993; Johnsen and others, 1997).

The two isotope records show correlation for the upper $2700 \mathrm{~m}$ (Alley and others, 1995). Below this depth, however, large discrepancies between the records begin to occur. The bottom $500 \mathrm{~m}$ span ice older than $60 \mathrm{kyr}$ including the entire Eemian interglacial 115-135 kyr BP. This climatic period is of special interest because of what we might learn about the stability of the current climate. Below $2700 \mathrm{~m}$, the isotope records from the two ice cores differ and cannot be correlated. Since the two drill sites are situated so close to each other, the large differences in the two records have been regarded as an artifact arising from disturbed stratigraphy due to the bedrock undulations and flow patterns unique to the basal zone (Thorsteinsson and others, 1997).

In order to obtain a more reliable Eemian record, a search was initiated for a new drill site. Since the disturbances are constrained to the basal zone, the principal search criterion was to have the Eemian layer located relatively high in the core over a relatively flat bed. The search

${ }^{1}$ GRIP is located at $72.60^{\circ} \mathrm{N}, 37.62^{\circ} \mathrm{W}(3232 \mathrm{~m})$ and GISP2 at $72.6^{\circ} \mathrm{N}, 38.5^{\circ} \mathrm{W}(3200 \mathrm{~m})$.

${ }^{2}$ NorthGRIP is situated on an ice ridge at $75.12^{\circ} \mathrm{N}, 42.30^{\circ} \mathrm{W}$, $316 \mathrm{~km}$ north-northwest of the GRIP drill site. was restricted to ice ridges in order to minimize the shear stress, which simplifies the interpretation. Among other criteria were: (1) an accumulation rate so low that the Eemian ice is far from the bedrock without basal melting, (2) little horizontal flow, and (3) no melting at the bed (Dahl-Jensen and others, 1997).

Radio-echo soundings were carried out along the ice ridge north of Summit (Chuah and others, 1996). These measurements show the depth of internal reflectors within the ice. Each reflector is believed to represent an event such as a volcanic eruption or abrupt change in climate and can be thought of as an isochrone. It is not possible to distinguish reflectors in the lower half of the profile. Therefore, the depth of the Eemian needed to be predicted by using a flow model that best fit the observed isochrones. The bedrock temperature was calculated using a combined flow/heat model. On these grounds, the NorthGRIP drill site was chosen. ${ }^{2}$ The predicted depth of the Eemian at NorthGRIP was 2750-2850m.

The drilling of NorthGRIP has reached $3001 \mathrm{~m}$, and the Eemian has not yet been found. Therefore the expectations have clearly not been met. This suggests that the flow history is different from that modelled during the search. In order to obtain a better understanding of the flow, a simple model with a few more degrees of freedom than the one used in the search has been used here. The inverse Monte Carlo analysis will then be applied to find the most likely model parameters.

\section{THE D.J. FLOW MODEL}

Because little is known about the flow in this region, a Dansgaard-Johnsen (D.J.) type flow model has been selected (Dansgaard and Johnsen, 1969). This model has few parameters, can be solved analytically and allows very large timesteps, factors which make it suitable for inclusion in a Monte 
Carlo algorithm. The D.J. model can be described by the following equations.

The coordinate system $(x, y, z)$ is placed so the $x$ axis runs along the ridge in the direction of the flow at NorthGRIP. The $z$ axis is the vertical height above bedrock. The flow at NorthGRIP is $1.329 \pm 0.015 \mathrm{~m} \mathrm{a}^{-1}$ along the ice ridge (Hvidberg and others, 2002). The velocity field $(U, V, W)$ is thus described by $U$ and $W$, defined as:

$$
\begin{aligned}
U(z) & =f(z) U_{\text {surface }} \\
& =\left\{\begin{array}{ll}
U_{\text {surface }} & z \in[h ; H] \\
{\left[F_{\mathrm{B}}+\left(1-F_{\mathrm{B}}\right) \frac{z}{h}\right] U_{\text {surface }}} & z \in[0 ; h]
\end{array},\right.
\end{aligned}
$$

where $f(z)$ is a shape factor, $H$ is the ice thickness in ice equivalent, and $h$ is a characteristic height above the bedrock. The surface velocity, $U_{\text {surface, }}$ and the bedrock velocity, $U_{\text {bed, }}$, are boundary conditions. $F_{\mathrm{B}}=U_{\text {bed }} / U_{\text {surface }}$ is the fraction of bottom sliding.

The vertical velocity is given by Dansgaard and Johnsen (1969):

$$
W(z)= \begin{cases}W_{0}-\frac{R h\left(F_{\mathrm{B}}+1\right)}{2}-R(z-h) & z \in[h ; H] \\ W_{0}-R z\left(F_{\mathrm{B}}+\left(1-F_{\mathrm{B}}\right) \frac{z}{2 h}\right) & z \in[0 ; h]\end{cases}
$$

$$
R=\frac{\partial U_{\text {surface }}}{\partial x}=\frac{a+W_{0}-(\mathrm{d} H / \mathrm{d} t)}{H-\left(1-F_{\mathrm{B}}\right) \frac{h}{2}},
$$

where the accumulation rate, $a$, and the basal melting rate, $-W_{0}$, both in ice equivalent, are the boundary conditions.

In the calculations, $a, W_{0}$ and $F_{\mathrm{B}}$ are assumed to be timedependent as described in the following sections, while $h$ and $H$ are assumed to remain constant. The parameter $h$ is unknown and must be determined by the Monte Carlo inversion.

\section{AGCUMULATION MODEL}

The past accumulation rates are calculated using a model similar to that developed for the dating of the GRIP ice core (Johnsen and others, 1997). The model relates the accumulation rate to the $\delta^{18} \mathrm{O}$ value:

$$
\begin{aligned}
& a=a_{0} \mathrm{e}^{k_{2}\left(\delta^{18} \mathrm{O}_{\mathrm{GRIP}}-\delta^{18} \mathrm{O}_{\mathrm{w}}\right)-\frac{1}{2} k_{1}\left(\delta^{18} \mathrm{O}_{\mathrm{GRIP}}^{2}-\delta^{18} \mathrm{O}_{\mathrm{w}}^{2}\right)}, \\
& k_{1}=\frac{R_{\mathrm{w}}^{a}-R_{\mathrm{c}}^{a}}{\delta^{18} \mathrm{O}_{\mathrm{w}}-\delta^{18} \mathrm{O}_{\mathrm{c}}}, k_{2}=R_{\mathrm{w}}^{a}-k_{1} \delta^{18} \mathrm{O}_{\mathrm{w}}
\end{aligned}
$$

in which a present-day value $\delta^{18} \mathrm{O}_{\mathrm{w}}=-35.2 \%$ and a glacial value $\delta^{18} \mathrm{O}_{\mathrm{c}}=-40.0 \%$ are defined. $a_{0}$ is the present-day accumulation rate at NorthGRIP. The time-dependent $\delta^{18} \mathrm{O}$ value is taken from the GRIP data. $R_{\mathrm{w}}^{a}$ and $R_{\mathrm{c}}^{a}$ are the relative slopes of $a\left(\delta^{18} \mathrm{O}_{\mathrm{GRIP}}\right)$.

$$
R_{\mathrm{w}}^{a}=\left.\frac{1}{a} \frac{\partial a}{\partial \delta^{18} \mathrm{O}}\right|_{\delta^{18} \mathrm{O}=\delta^{18} \mathrm{O}_{\mathrm{w}}}, R_{\mathrm{c}}^{a}=\left.\frac{1}{a} \frac{\partial a}{\partial \delta^{18} \mathrm{O}}\right|_{\delta^{18} \mathrm{O}=\delta^{18} \mathrm{O}_{\mathrm{c}}}
$$

The relative slopes $R_{\mathrm{w}}^{a}$ and $R_{\mathrm{c}}^{a}$ are unknown constant parameters.

\section{MELT AND SLIDING MODEL}

The basal melt rate $-W_{0}$ can be calculated directly by assuming energy balance (Paterson, 1994).

$$
-W_{0}=\left\{\begin{array}{cc}
0 & G \leq Q_{\mathrm{c}} \\
\frac{G-Q_{\mathrm{c}}}{\rho L} & G>Q_{\mathrm{c}}
\end{array},\right.
$$

$\rho$ being the density of ice, $L$ the specific latent heat of fusion and $G$ the geothermal heat flux which is assumed to be constant in time. $Q_{\mathrm{c}}$ is the heat flux which is transferred from the bed through the ice.

A simple heat-flow model is used to make an estimate of $Q_{\mathrm{c}}$ :

$$
k \frac{\mathrm{d}^{2} T}{\mathrm{~d} z^{2}}-w \frac{\mathrm{d} T}{\mathrm{~d} z}=0
$$

where $k$ is the thermal diffusivity and the vertical velocity is assumed to be $w=-a(H-z) / h$. The model is steady-state, one-dimensional and ignores internal heat generation. Knowing the boundary conditions $T_{\text {surface }}$ and $(\mathrm{d} T / \mathrm{d} z)_{\text {base }}$ $=-Q_{\mathrm{c}} / K$, the following relation can be calculated analytically (Paterson, 1994):

$$
T_{\text {surface }}-T_{\text {bed }}=\frac{-Q_{\mathrm{c}} \sqrt{\pi}}{K} \int_{0}^{H}-\frac{z^{2} a}{2 k H} \mathrm{~d} z .
$$

For the conditions at NorthGRIP, Equation (7) can be approximated by

$$
\begin{aligned}
T_{\text {surface }}-T_{\text {bed }} & =-\sqrt{\frac{k H \pi}{2 a K^{2}}} Q_{\mathrm{c}} \Leftrightarrow \\
Q_{\mathrm{c}} & =\sqrt{\frac{2 a K^{2}}{k H \pi}}\left(T_{\text {bed }}-T_{\text {surface }}\right) .
\end{aligned}
$$

Now $Q_{\mathrm{c}}$ can be calculated as a function of surface temperature and accumulation rate, assuming that the basal ice is at the pressure-melting point $\left(T_{\text {bed }}=-2.4^{\circ} \mathrm{C}\right)$. In this estimate, the relation between the surface temperature and the $\delta^{18} \mathrm{O}$ values has been taken from Johnsen and others (1995).

If $G$ is less than $Q_{\mathrm{c}}$, basal melting is discarded and we set $Q_{\mathrm{c}}=G$. The model gives a rough estimate of the $Q_{\mathrm{c}}$ value to be used in the Monte Carlo calculations. It does not account for the time needed to reach steady-state temperature profiles in the ice. The next development would be to include a true time-dependent heat energy model.

The fraction of sliding is modelled assuming that $F_{\mathrm{B}}$ is linearly dependent on the melt rate:

$$
F_{\mathrm{B}}=\min \left(\frac{\mathrm{d} F_{\mathrm{B}}}{\mathrm{d} W_{0}} W_{0}, 1\right) .
$$

The main differences between the collective model presented here and the model used during the search are that the new model allows for the melt rate $\left(W_{0}\right)$ and the fraction of sliding $\left(F_{\mathrm{B}}\right)$ to be non-zero. Furthermore, it has an independent accumulation model.

\section{MONTE GARLO INVERSION}

The combined model has five unknown model parameters: $h$ from the flow model (Equation (2)), $G$ and $\mathrm{d} F_{\mathrm{B}} / \mathrm{d} W_{0}$ from the melt and sliding model (Equations (5) and (9)) and $R_{\mathrm{w}}^{a}$ and $R_{\mathrm{c}}^{a}$ from the accumulation model (Equation (3)). Each combination of these parameters constitutes a model $(\mathbf{m})$ in the five-dimensional model space. The observed dataset ( $\mathbf{d}_{\text {obs }}$ ) consists of age/depth horizons (fix points) determined in the NorthGRIP ice core. To evaluate the quality of a 
modelled dataset $\left(\mathbf{d}_{\text {model }}\right)$, a likelihood function $L(\mathbf{m})$ is defined. This is done by introducing a misfit function $S(\mathbf{m})$ :

$$
S(\mathbf{m})=\sum_{i} \frac{\left|d_{\text {obs }}^{i}-d_{\text {model }}^{i}\right|}{\sigma^{i}} .
$$

The likelihood function takes the form $L(\mathbf{m})=c \mathrm{e}^{-S(\mathbf{m})}$, where $\mathrm{c}$ is a normalization constant. The uncertainties $\left(\sigma^{i}\right)$ in $\mathbf{d}_{\text {obs }}$ originate primarily from uncertainties in the GRIP time-scale. Hence, uncertainties are estimated by comparing four different time-scales of GRIP and GISP2, looking at specific events such as the Z2 ash layer and the Campanian Ignimbrite event. These uncertainties in years are then converted to NorthGRIP depths using $\mathbf{d}_{\text {obs. }}$

In order to determine the flow history, this dataset is inverted into a probability distribution of the five model parameters, being interested not only in the most likely model, but also in the resolution power. The direct way to do this is to make an exhaustive search of the entire model space, and store the likelihood of each point. The resulting distribution is called the posterior-probability distribution (Mosegaard, 1998). However, this is not feasible since it requires huge amounts of storage and processing power.

Inverse Monte Carlo sampling is an importance sampling method which can significantly reduce the number of calculations needed to estimate the posterior-probability distribution. In the Monte Carlo scheme used here, a random walk is made in the model space. A perturbed model $\mathbf{m}_{\text {test }}$ of the current model $\mathbf{m}_{\text {current }}$ is proposed. The perturbed model becomes the next model according to an acceptance probability

$$
P_{\text {accept }}=\min \left(\frac{L\left(\mathbf{m}_{\text {test }}\right)}{L\left(\mathbf{m}_{\text {current }}\right)}, 1\right) .
$$

The resulting set of accepted models can be shown to be sampled according to the posterior-probability density (Mosegaard and Tarantola, 1995). The frequency of accepted models, in a subspace of the model space, indicates how probable models are in this area. It is also worth noting that a mean of a model parameter over all the accepted models can be regarded as a posterior-probability weighted mean.

\section{DISGUSSION}

The random walk was continued until a total of 200000 models were accepted. Histograms of all model parameters can be seen in Figure 1. These histograms represent the relative likelihood of the model parameters.

The flow kink point $h$ has the value $2310 \pm 333 \mathrm{~m}$ (Fig. 1b). The probability distribution for $h$ shows multiple maxima. The Monte Carlo analysis fails to find an unambiguous value because the specific choice of $h$ has little impact on the misfit when $F_{\mathrm{B}}$ is high. Luckily, the effect on the inversion of the other parameters is small.

The Monte Carlo-tuned NorthGRIP accumulationmodel parameters were found to have values $R_{\mathrm{w}}^{a}=0.22$ $\pm 0.02 \%{ }^{-1}$ and $R_{\mathrm{c}}^{a}=0.14 \pm 0.03 \%{ }^{-1}$ (Fig. lc and d). The accumulation ratio $a_{\text {NorthGRIP }} / a_{\text {GRIP }}$ was expected to be constant through different climatic conditions. As seen in Figure 2 , this is not the case. The accumulation pattern seen today was more pronounced during glacial times. The present-day relative accumulation pattern shows that the accumulation rate at NorthGRIP is $83 \%$ of that at GRIP. During glaciation, it was as low as $66 \%$ of that at GRIP.

The geothermal heat flux at NorthGRIP implied by the Monte Carlo method is $98 \pm 7 \mathrm{~mW} \mathrm{~m}^{-2}$ (Fig. la). This is
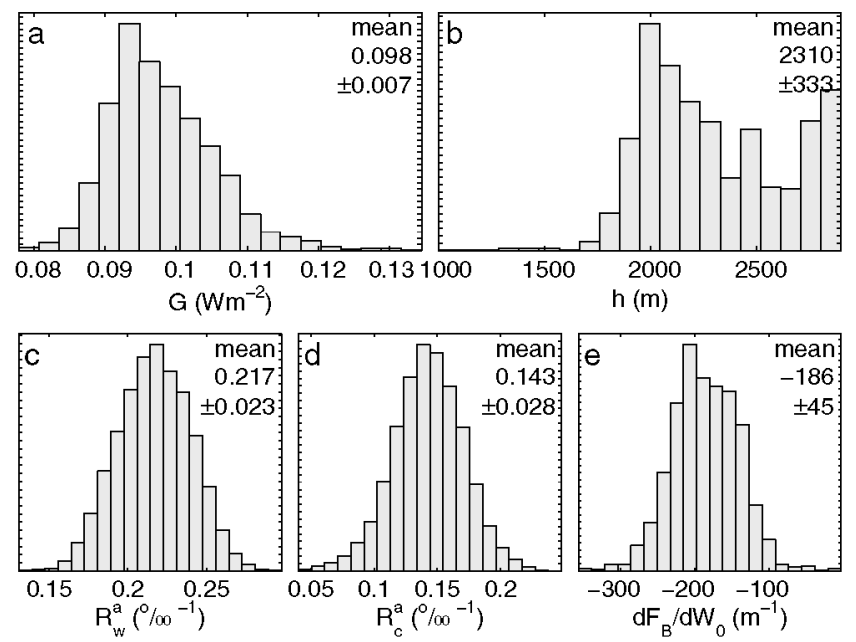

Fig. 1. Probability distributions for the model parameters derived from inverse Monte Carlo analysis. (a) The geothermal heat flux, G, (Equation (5)) at NorthGRIP is approximately double the expected $51 \mathrm{~mW} \mathrm{~m}^{-2}$. (b) The kink point $h$ of the D.F. flow model (Equation (1)). (c,d) The relative slopes of a warm and a cold control point, respectively, in the accumulation model (Equation (3)). (e) The dependence of the fraction of sliding upon the basal melt rate (Equation (9)). The mean model corresponds to a mean fraction of sliding of $41 \%$ during the Holocene and 53\% under glacial conditions.

twice the value of the Precambrian shield $\left(51 \mathrm{~mW} \mathrm{~m}^{-2}\right)$ which is believed to cover most of Greenland. Since there is no melting at GRIP, the geothermal heat flux at GRIP can be directly observed to be $51 \mathrm{~mW} \mathrm{~m}^{-2}$ (Dahl-Jensen and others, 1998). The change to $98 \mathrm{~mW} \mathrm{~m}^{-2}$ cannot be seen as a dip in the radio-echo-derived isochrones along the ridge. The mean model gives a mean melt rate of $2.2 \mathrm{~mm} \mathrm{a}^{-1}$ during the Holocene and $2.8 \mathrm{~mm} \mathrm{a}^{-1}$ during the glacial.

The probability distribution of $\mathrm{d} F_{\mathrm{B}} / \mathrm{d} W_{0}$ (Fig. le) has a mean of $\mathrm{d} F_{\mathrm{B}} / \mathrm{d} W_{0}=-186 \pm 45$ years $\mathrm{m}^{-1}$. Using the mean model, this corresponds to a mean fraction of sliding of $41 \%$ and $53 \%$ for the Holocene and glacial periods, respectively.
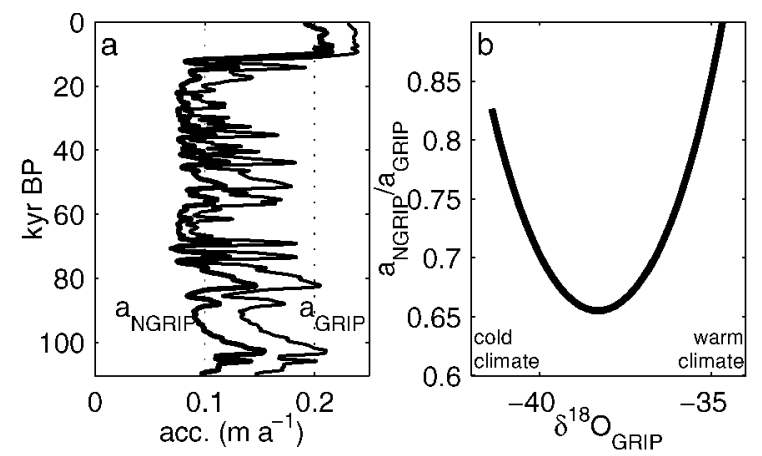

Fig. 2. (a) The accumulation rate at NorthGRIP derived from the modelled parameters. The thin curve shows the accumulation rate at GRIP (Fohnsen and others, 1995) in comparison. (b) The ratio of the accumulation rates for GRIP and NorthGRIP. Both accumulation models are a function of $\delta^{18} \mathrm{O}_{\mathrm{GRIP}}$. During glacial conditions the ratio $a_{\mathrm{NorthGRIP}} / a_{\mathrm{GRIP}} w$ as as low as $80 \%$ of present-day values. 


\section{CONGLUSIONS}

The reason no Eemian is seen in the NorthGRIP ice core is that there is melting at the bottom. From the Monte Carlo analysis it is concluded that the geothermal heat flux at NorthGRIP is $98 \pm 7 \mathrm{~mW} \mathrm{~m}^{-2}$. This is considerably higher than the value for the Precambrian shield which is believed to cover most of Greenland. From bottom topography maps it is seen that the bedrock is very flat in the NorthGRIP area. One possible explanation for the flatness and higher heat flux might be that the bed beneath NorthGRIP is composed of sediments.

At present the accumulation rate at NorthGRIP is $83 \%$ of that at GRIP. During the glaciation it was as low as $66 \%$ of that at GRIP (Fig. 2).

For the mean model it can be calculated that the mean melt rate at NorthGRIP is $2.7 \mathrm{~mm} \mathrm{a}^{-1}$ and the mean fraction of sliding is $50 \%$, for the past $89 \mathrm{kyr}$.

The model presented here predicts the depth of the Eemian to be $2890 \mathrm{~m}$. This is at least $110 \mathrm{~m}$ too high in the core. The simple model presented here cannot give a correct prediction of the Eemian without losing the fit on the fix points younger than $89 \mathrm{kyr}$. This suggests that the oldest ice at NorthGRIP has experienced a higher melting upstream. A zone of increased divergence is found $120 \mathrm{~km}$ upstream from NorthGRIP. In Hvidberg and others (2002) it is estimated that ice older than $90 \mathrm{kyr}$ has been influenced by the flow in this region.

During the search for the NorthGRIP ice-core drilling site, modelling showed that the basal ice at NorthGRIP had been close to the melting point (Dahl-Jensen and others, 1997). The 52 kyr BP radio-echo horizon was the oldest horizon used to tune the models. We should not put too much trust in models which are not well constrained by observations. In retrospect, high modelled basal temperatures should have served as a warning of a relatively high probability of basal melting.
Although the goal of obtaining a core with a good Eemian record was not achieved, the melting had the fortunate sideeffect that it stretched the glacial record. The NorthGRIP core has the highest resolution yet of the $110 \mathrm{kyr}$ glacial period.

\section{REFERENGES}

Alley, R. B., A. J. Gow, S. J. Johnsen, J. Kipfstuhl, D. A. Meese and Th. Thorsteinsson. 1995. Comparison of deep ice cores. Nature, 373(6513), 393-394.

Chuah, T. S., S. P. Gogineni, C. Allen and B. Wohletz. 1996. Radar thickness measurements over the northern part of the Greenland ice sheet. Lawrence, KS, University of Kansas Center for Research Inc. Radar Systems and Remote Sensing Laboratory. (Technical Report 10470-3.)

Dahl-Jensen, D. and 9 others. 1997. A search in north Greenland for a new icecore drill site. 7. Glaciol., 43(144), 300-306.

Dansgaard, W. and S. J. Johnsen. 1969. A flow model and a time scale for the ice core from Camp Century, Greenland. F. Glaciol., 8(53), 215-223.

Dansgaard, W. and 10 others. 1993. Evidence for general instability of past climate from a 250-kyr ice-core record. Nature, 364(6434), 218-220.

Grootes, P. M., M. Stuiver, J.W. C. White, S. Johnsen and J. Jouzel. 1993. Comparison of oxygen isotope records from the GISP2 and GRIP Greenland ice cores. Nature, 366(6455), 552-554.

Hvidberg, C. S., K. Keller and N. S. Gundestrup. 2002. Mass balance and ice movement along the NNW ridge of the Greenland ice sheet at NorthGRIP. Ann. Glaciol., 35 (see paper in this volume).

Johnsen, S. J., D. Dahl-Jensen, W. Dansgaard and N. S. Gundestrup. 1995. Greenland paleotemperatures derived from GRIP borehole temperature and ice core isotope profiles. Tellus, 47B(5), 624-629.

Johnsen, S. J. and 14 others. 1997. The $\delta^{18} \mathrm{O}$ record along the Greenland Ice Core Project deep ice core and the problem of possible Eemian climatic instability. F. Geophys. Res., 102(C12), 26,397-26,410.

Mosegaard, K. 1998. Resolution analysis of general inverse problems through inverse Monte Carlo sampling. Inverse Problems, 14(1), 405-426.

Mosegaard, K. and A. Tarantola. 1995. Monte Carlo sampling of solutions to inverse problems. F. Geophys. Res., 100(B7), 12,431-12,447.

Paterson, W. S. B. 1994. The physics of glaciers. Third edition. Oxford, etc., Elsevier.

Thorsteinsson, Th., J. Kipfstuhl and H. Miller. 1997. Textures and fabrics in the GRIP ice core. F. Geophys. Res., 102(C12), 26,583-26,599.

Wang, Y., T. Thorsteinsson, J. Kipfstuhl, H. Miller, D. Dahl-Jensen and H. Shoji. 2002. A vertical girdle fabric in the NorthGRIP deep ice core, North Greenland. Ann. Glaciol., 35 (see paper in this volume). 